\title{
Fingerprint Identification using Sectorized Cepstrum Complex Plane
}

\author{
Dr. H.B. Kekre \\ Senior Professor, Department of \\ Computer Science, \\ Mukesh Patel School of Technology \\ Management and Engineering \\ Mumbai, India
}

\author{
Dr. Tanuja Sarode \\ Assistant Professor, \\ TSEC, Bandra (W), \\ Mumbai, 400-050, India
}

\author{
Rekha Vig \\ Assistant Professor and Research \\ Scholar, Department of Electronics \\ and Telecommunication \\ Mukesh Patel School of Technology \\ Management and Engineering
}

\begin{abstract}
Using biometrics to verify a person's identity has several advantages over the present practices of personal identification numbers (PINs) and passwords. Minutiae-based automated fingerprint identification systems are more popular, but they are more computationally complex and time consuming. In this paper we propose a simple yet effective technique for fingerprint identification. This method is image-based in which feature vectors of a fingerprint are extracted after sectorization of the cepstrum of a fingerprint. They are matched with those stored in the database. The experimental results show that this algorithm could correctly identify fingerprints with accuracy more than $96 \%$ in case of larger number of sectors.
\end{abstract}

\section{General Terms}

Pattern Recognition, Security, Biometrics.

\section{Keywords}

Sectorization; Cepstrum; frequency domain; fingerprint identification.

\section{INTRODUCTION}

Fingerprint identification remains as one of the most widely used and reliable biometric identification methods [1]. Even after decades of research, fingerprint identification is still a very challenging area. The age old method of fingerprint identification which has been done manually is based on minutiae detection. Minutiae are the identification points which are mostly ridge endings and ridge bifurcation points, and others like ridge crossovers, islands etc. The fingerprint identification process includes locating the position, type and number of these minutiae. As the database of fingerprints increased manual identification became tedious and automated methods became more widespread. Fingerprint verification and identification algorithms [11] can be classified into two categories: image-based and minutiae-based. Image-based methods include methods involving optical correlation [3] and transform-based features [2], [5], [6], [7]. Other aspects of fingerprint identification are orientation [8], segmentation [9] and core point detection [10]. They may achieve higher computational efficiency than minutiae based methods. In addition, they may be the only choice when the image quality of the given fingerprint is low. Most of the current automated systems are based on minutiae tracking, but these algorithms are easily affected by orientation and shift of fingerprint. Hence they are less reliable, more complex and time consuming.

This paper discusses the use of automated technique of fingerprint identification which takes the fingerprint in totality and identification is done by analyzing the overall features of fingerprint like texture etc. Since the ridges on the fingerprint form repetitive patterns, its frequency domain representation has unique characteristics which are used here for identification purpose.

The rest of the paper is structured as follows. Section II describes the Fourier transform technique. Section III explains the proposed sectorization method. The experimental results are given in section IV. Finally, conclusions are given in section $\mathrm{V}$.

\section{FREQUENCY DOMAIN ANALYSIS}

\section{FOURIER TRANSFORM}

The Fourier transform is a powerful tool of linear system analysis. For discrete functions (images) of two dimensions, the discrete Fourier transform is defined as [4]:

$F\left(u_{v} v\right)=\frac{1}{M N} \sum_{x=0}^{M-1} \sum_{y=0}^{N-1} f\left(x_{w} y\right) \exp \left[-j 2 \pi\left(\frac{u x}{M}+\frac{v y}{N}\right)\right]$

where $\mathrm{u}$ and $\mathrm{v}$ are two dimensional frequency representation. The magnitude of the Fourier spectrum is given by its absolute value as,

$$
|F(u, v)|=\sqrt{R(u, v)^{2}+I(u, v)^{2}}
$$


where, $\mathrm{R}(\mathrm{u}, \mathrm{v})$ and $\mathrm{I}(\mathrm{u}, \mathrm{v})$ are the real and imaginary components of the complex Fourier transform value. Each pixel in Fourier spectrum represents an intensity change in spatial frequency of one cycle per image width. The ring showed in Fig. 1 is produced by the periodic and uniform intensity changes which represents the ridge-valley structure in a fingerprint image.
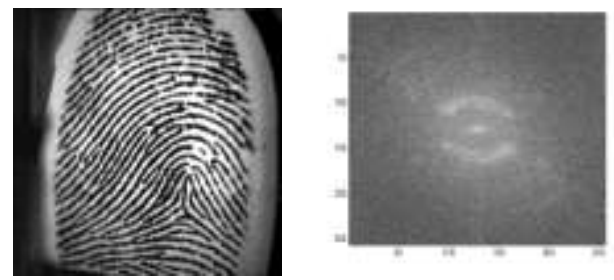

Figure 1.Fingerprint and its Cepstrum

The logarithm of the Fourier spectrum is referred to as cepstrum which represents the power in frequency domain.

$$
\mathrm{S}(\mathrm{u}, \mathrm{v})=10 * \log (\mathrm{F}(\mathrm{u}, \mathrm{v})
$$

The cepstrum of a fingerprint image is directly related to the power content of that fingerprint. Hence, here we are directly dealing with power concentrated in each fingerprint. The spectrum is first shifted to represent the zero frequency at the centre of the complex plane. A block of $160 \times 160$ pixels is then extracted from the centre point as most of the information is contained in this region. The region outside this block contains less amount of information and adds to the computation complexity.

\section{SECTORIZATION}

The complex 2D plane of Fourier spectrum (block of $160 \mathrm{x}$ 160) pixels is divided into different sectors. For each sector a feature vector is generated which is the mean of the cepstrum value of all the points in that sector. This value is unique for each fingerprint as the frequency distribution of each fingerprint is unique in different sectors. Sectorization helps is generating fewer feature vectors vis-à-vis when comparing the entire or those transform coefficients which contain major part of signal energy.

The complex 2D plane is divided into $4,8,12$ or 16 sectors as shown in the figure 2 based on the criteria as shown in the tables (Table I - IV). Here first the complex plane is divided into 4 sectors which have the same sequence as those of the quadrants of a plane as shown in figure 2 .

For higher division i.e. 8, 12 and 16 sectors, these 4 sectors are considered as individual blocks and the criteria shown in the respective tables are applied where $\mathrm{x}$ represents the row number and y represents the column number.
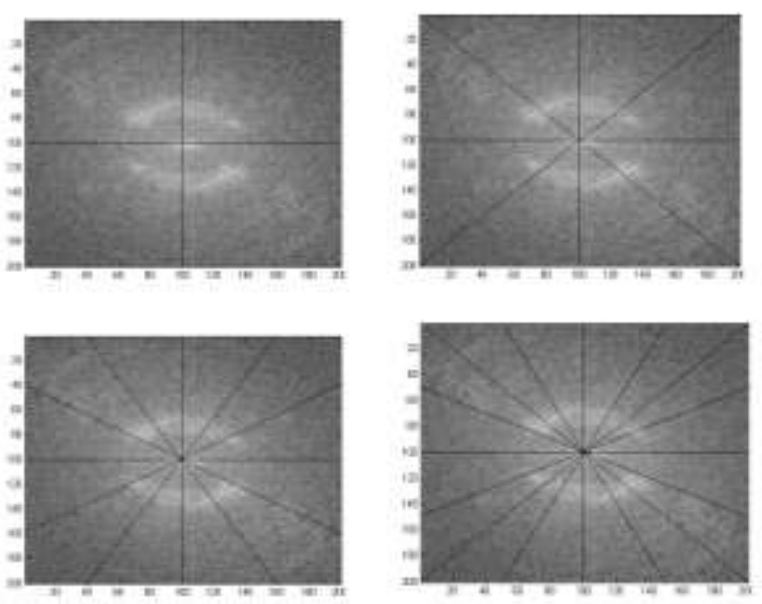

Figure 2. a) 4 sectors b) 8 sectors c) 12 sectors d) 16 sectors

TABLE I. FOUR SECTORS

\begin{tabular}{|l|l|}
\hline Sectors & Locations \\
\hline I & Top right quadrant (QI) \\
\hline II & Top left quadrant (QII) \\
\hline III & Bottom left quadrant (QIII) \\
\hline IV & Bottom right quadrant (QIV) \\
\hline
\end{tabular}

TABLE II. EIGHT SECTORS

\begin{tabular}{|l|l|}
\hline Sectors & Criteria \\
\hline I, IV, VI and VII & If $\mathrm{x}<\mathrm{y}$ \\
\hline II, III, V and VIII & If $\mathrm{x}>=\mathrm{y}$ \\
\hline
\end{tabular}

TABLE III. TWELVE SECTORS

\begin{tabular}{|l|l|}
\hline Sectors & Criteria \\
\hline I, VI, VII and XII & If $\mathrm{x}<\mathrm{ytan}(\pi / 6)$ \\
\hline II, V, VIII and XI & If $\mathrm{x}>=\mathrm{ytan}(\pi / 6))$ and $(\mathrm{x}<\mathrm{ytan}(\pi / 3)$ \\
\hline III, IV, IX and X & If $\mathrm{x}>=\mathrm{ytan}(\pi / 3)$ \\
\hline
\end{tabular}

TABLE VI. SIXTEEN SECTORS

\begin{tabular}{|l|l|}
\hline Sectors & Criteria \\
\hline I, VIII, IX and XVI & If $\mathrm{x}<\mathrm{ytan}(\pi / 8)$ \\
\hline II, VII, X and XV & If $\mathrm{x}>=\mathrm{y} \tan (\pi / 8))$ and $(\mathrm{x}<\mathrm{ytan}(\pi / 4)$ \\
\hline III, VI, XI and XIV & If $\mathrm{x}>=\mathrm{y} \tan (\pi / 4))$ and $(\mathrm{x}<\mathrm{ytan}(3 \pi / 8)$ \\
\hline IV, V, XII, XIII & If $\mathrm{x}>=\mathrm{ytan}(3 \pi / 8)$ \\
\hline
\end{tabular}


The mean of the cepstrum value of all the points for $\mathrm{k}^{\text {th }}$ sector is calculated as,

$$
M_{\mathrm{k}}=\frac{1}{N} \sum_{i=1}^{w} S_{i}(u, v)
$$

where, $\mathrm{N}$ is the total number of points in a sector. These mean values represent the feature vectors, along with the zero frequency cepstrum value as a separate feature vector. Hence for 16 sectors there are 17 feature vectors. These features obtained from the test image are compared with those obtained from the stored fingerprint and the results matched. The Euclidian distances between the feature vectors of the test image and the database images are calculated. The minimum distance gives the best match. Larger the number of sectors better the accuracy in fingerprint identification.

\section{EXPERIMENTAL RESULTS}

This unique and novel method has been tested over a large database of 168 images. Total of 21 images with 8 samples of each, obtained with rotational $\left(+/-15^{\circ}\right)$ and shift (horizontal and vertical) variations have been considered. The algorithm compared the feature vectors of the test image with those in database and the first 8 matched were recorded. Also whether the first match belonged to the same fingerprint or not was recorded. The results have been tabulated in Table V and VI and it has been observed that there is considerable improvement with increase in number of sectors as shown in figure 3 and 4 . We have applied the proposed technique on these images and results in each category show that our method can satisfactorily identify the fingerprint images. The accuracy rate observed is more than $96 \%$ for 16 sectors

TABLE V.

\begin{tabular}{|c|c|}
\hline Sectors & $\begin{array}{c}\text { No. of Matches } \\
(\text { Avg) in the first } 8 \\
\text { matches }\end{array}$ \\
\hline 4 & 3.09677 \\
\hline 8 & 4.5666 \\
\hline 12 & 5.129 \\
\hline 16 & 5.2903 \\
\hline
\end{tabular}

TABLE IV.

\begin{tabular}{|c|c|}
\hline Sectors & $\begin{array}{c}\text { Accuracy (in } \\
\text { terms of first } \\
\text { position match) }\end{array}$ \\
\hline 4 & $40.32 \%$ \\
\hline 8 & $71.24 \%$ \\
\hline 12 & $87.09 \%$ \\
\hline 16 & $96.77 \%$ \\
\hline
\end{tabular}

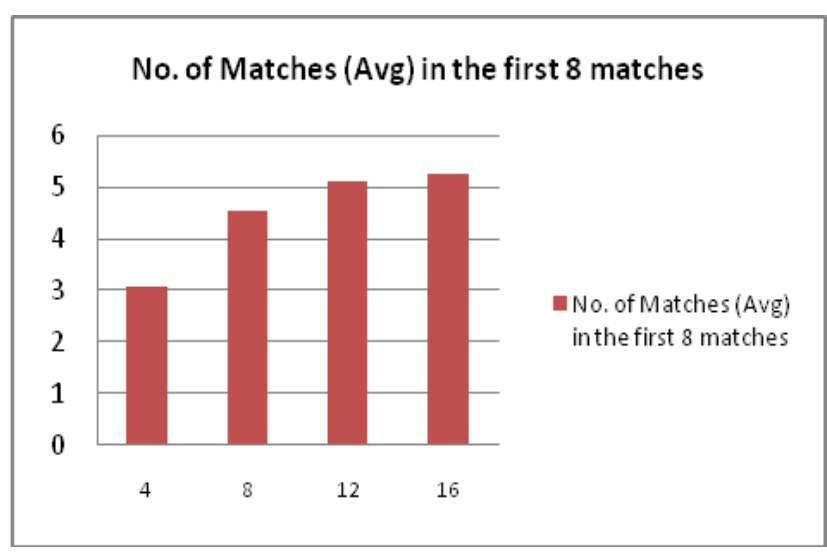

Figure 3.Average number of matches in the first 8 matches for different sectors

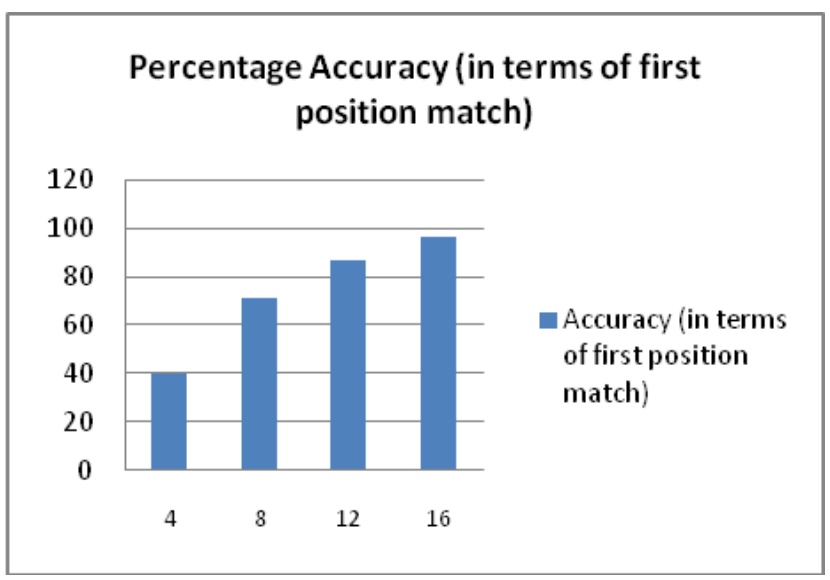

Figure 4. Accuracy obtained for different sectors

\section{CONCLUSION}

In this paper, we have proposed a novel method for reliable identification of fingerprint images. The technique of sectorization of the cepstrum of fingerprint images has been used to generate feature vectors and matching is done using Euclidean distance as similarity measure. This method is 
computationally very simple and fast as the recognition procedure does not include multiple steps as compared to the methods where minutea detection is used for fingerprint recognition. It also is considerably independent of shift and rotation of fingerprint images. The results show that this simple and robust method can be effectively used for fingerprint identification.

\section{REFERENCES}

[1] D. Maltoni, D. Maio, A. Jain, and S. Prabhakar, Handbook of Fingerprint Recognition. New York: Springer, 2003.

[2] L. Jain et al., Intelligent Biometric Techniques in Fingerprint and Face Recognition, CRC Press, 1999.

[3] F. Gamble, L. Frye, and D. Grieser, "Real-time Fingerprint Verification System," Applied Optics, vol. 31, no. 5, 1992, pp.652-655.

[4] Gonzalez Rafael C., Woods Richard E., "Digital Image Processing," 3rd edition. Prentice Hall, 2008.

[5] H. B. Kekre, Tanuja K. Sarode, Vinaya M. Rawool, "Finger Print Identification using Discrete Sine Transform (DST)" International Conference on Advanced Computing \& Communication Technology (ICACCT-2008) Asia Pacific Institute of Information Technology, Panipat India 8-9 Nov 2008

[6] H. B. Kekre, Tanuja K. Sarode, Vinaya M. Rawool, "Fingerprint Identification using Principle Component Analysis (PCA)" International Conference on Computer Networks and Security (ICCNS08) held at VIT Pune, 2728,September 2008

[7] H. B. Kekre, Tanuja K. Sarode, Sudeep D. Thepade, DCT Applied to Column Mean and Row Mean Vectors of Image for Fingerprint Identification" International Conference on Computer Networks and Security (ICCNS08) held at VIT Pune, 27-28,September 2008

[8] H. B. Kekre, V. A. Bharadi, "Fingerprint Orientation Field Estimation Algorithm Based on Optimized Neighborhood Averaging" 2nd International Conference on Emerging Trends in Engineering \& Technology (ICETET_09) 16-18 December 2009, G.H. Raisoni College of Engineering, Nagpur, India. Cited on line at IEEE Xplore

[9] H. B. Kekre, V. A. Bharadi, "Fingerprint \& Palmprint Segmentation by Automatic Thresholding of Gabor Magnitude" 2nd International Conference on Emerging Trends in Engineering \& Technology (ICETET_09) 16-18 December 2009, G.H. Raisoni College of Engineering, Nagpur, India. Cited on line at IEEE Xplore

[10]H. B. Kekre, V. A. Bharadi, "Fingerprint's Core Point Detection Using Orientation Field" International Conference on Advances in Computing, Control, \& Telecommunication Technologies, 2009. (ACT '09),28-29 Dec 2009, Thiruvananthapuram, Kerala, Cited on line at IEEE Xplore

[11]A. K. Jain, J. Feng, A. Nagar and K. Nandakumar, "On Matching Latent Fingerprints", IEEE Computer Society Workshop on Biometrics, CVPR, Alaska, June 2008

\section{AUTHOR BIOGRAPHIES}

Dr. H. B. Kekre has received B.E. (Hons.) in Telecomm. Engg. from Jabalpur University in 1958, M.Tech (Industrial Electronics) from IIT Bombay in 1960, M.S.Engg. (Electrical Engg.) from University of Ottawa in 1965 and Ph.D. (System Identification) from IIT Bombay in 1970. He has worked Over 35 years as Faculty of Electrical Engineering and then HOD Computer Science and Engg. at IIT Bombay. For last 13 years worked as a Professor in Department of Computer Engg. at Thadomal Shahani Engineering College, Mumbai. He is currently Senior Professor working with Mukesh Patel School of Technology Management and Engineering, SVKM's NMIMS University, Vile Parle(w), Mumbai, INDIA. He ha guided 17 Ph.D.s, 150 M.E./M.Tech Projects and several B.E./B.Tech Projects. His areas of interest are Digital Signal processing, Image Processing and Computer Networks. He has more than 300 papers in National / International Conferences / Journals to his credit. Recently ten students working under his guidance have received best paper awards. Two of his students have been awarded Ph. D. of NMIMS University. Currently he is guiding ten Ph.D. students. He is member of ISTE and IETE.

Dr. Tanuja K. Sarode has Received Bsc.(Mathematics) from Mumbai University in 1996, Bsc.Tech.(Computer Technology) from Mumbai University in 1999, M.E. (Computer Engineering) from Mumbai University in 2004, currently Pursuing Ph.D. from Mukesh Patel School of Technology, Management and Engineering, SVKM's NMIMS University, Vile-Parle (W), Mumbai, INDIA. She has more than 10 years of experience in teaching. Currently working as Assistant Professor in Dept. of Computer Engineering at Thadomal Shahani Engineering College, Mumbai. She is life member of IETE, member of International Association of Engineers (IAENG) and International Association of Computer Science and Information Technology (IACSIT), Singapore. Her areas of interest are Image Processing, Signal Processing and Computer Graphics. She has 52 papers in National /International Conferences/journal to her credit.

Rekha Vig has received B.E. (Hons.) in Telecomm. Engg. from Jabalpur University in 1994 and M.Tech (Telecom) from MPSTME, NMIMS University in 2010. She is working as Assisstant Professor in the Department of Electronics and Telecommunications in Mukesh Patel School of Technology Management and Engineering, NMIMS University, Mumbai. She has more than 12 years of teaching and approximately 2 years of industry experience. She is currently pursuing her Ph.D. from NMIMS University, Mumbai. Her areas of specialization are image processing, digital signal processing and wireless communication. Her publications include two papers in IEEE international conferences, one in international conference (IVPCV) at Orlando, USA and some in national conferences and journal. 